\title{
Reflections on the theoretical advance in ethnobiology: are we pointing to the wrong direction?
}

Washington Soares Ferreira Júnior*

\begin{abstract}
Over the past 30 years, a series of ethnobiological studies has presented and discussed theoretical scenarios, new hypotheses to be tested, as well as relevant research questions based on dialogue with different disciplines. However, the production of these articles of important theoretical relevance has not accompanied an increase in the number of studies that contribute to the advancement of scientific knowledge in ethnobiology. In this manuscript, I discuss some of the main reasons that can lead to the large number of works that reflect little on their theoretical contributions, with the aim to minimize these problems, so we can favor the progress in the area for the coming years.
\end{abstract}

Keywords: Ethnobotany; Theoretical Contributions; Research agendas.

Laboratório de Investigações Bioculturais no Semiárido, Universidade de Pernambuco, Campus Petrolina, Rodovia BR 203, Km 2, s/n - Vila Eduardo, Petrolina, PE 56328-903, Brazil.

* Corresponding author. $₫ \mathrm{E}$-mail address: washington.ferreira@upe.br

\section{SIGNIFICANCE STATEMENT}

I contribute with the presentation of different aspects present in ethnobiological studies that do not favor the theoretical advancement of the area over time. Reflecting on the reasons that contribute to a low quality of studies, from a theoretical point of view, can help in directing future research that will allow advances in ethnobiology for the coming years.

\section{INTRODUCTION}

Understanding the relationships of human groups with different environments involves assessing the performance of different factors that model these relationships at multiple scales (Reyes-García et al. 2016; Albuquerque et al. 2019a). Ethnobiology, as a complex and interdisciplinary science, can contribute to the understanding of the mechanisms that act in people's interactions with their environments (particularly with biota) and, therefore, allow the construction of actions aimed at solving social-ecological challenges on the planet (Sõukand et al. 2020; Volpato et al. 2020). For ethnobiology 
to favor the understanding of peopleenvironment relations and their practical applications, it is necessary to reflect on how far this discipline has been advancing both theoretically and methodologically.

Some studies have been contributing to the theoretical advancement of ethnobiology, producing a set of questions and hypotheses that allow directing investigations to test their predictions in different environments. For example, Johns (1990) proposed the human chemical ecology model to investigate the complexity involved in the relationships between people and plants, for food and medicinal purposes, based on an ecological and evolutionary scenario. In another example, Phillips and Gentry (1993a) presented a hypothesis to explain the cultural importance of plants based on the availability of these resources in the environment, which is also based on an ecological scenario. Other studies, since the 1990s, have produced questions and hypotheses that reflect theoretical advances in ethnobiology (a synthesis of the hypotheses produced for ethnobotany can be found in Gaoue et al. 2017).

However, even with efforts made for theoretical advancement, a number of ethnobiological studies are descriptive, highlighting a list of useful resources and their uses in different human groups, failing to show a clear relationship with theoretical research questions and/or with the relevant hypotheses testing that is necessary for advancing in the field (Albuquerque and Hanazaki 2009). In addition, since the 1990s, there has been an increase in the number of studies using quantitative methods. However, these were not necessarily associated with original questions and hypothesis testing (Albuquerque 2009). This suggests that the presentation of questions, hypotheses and theoretical scenarios in different ethnobiological studies has not favored an improvement in the quality of studies.

It is evident that, in the last 10 years, a set of articles presented new proposals and theoretical reflections on ethnobiology, particularly from the interaction with different disciplines, such as ecology and evolution (Reyes-García et al. 2016; Gaoue et al. 2017; Albuquerque and Ferreira Júnior 2017; Albuquerque et al. 2019a). However, the publication of these studies does not guarantee an increase in future research (in the next 10 years) that incorporate these theoretical reflections to promote the advance in the knowledge of complex relationships between people and biota. Thus, here I intend to evaluate the reasons that lead to a predominance of studies that reflect little on their theoretical contributions to ethnobiology over time. Reflecting on these points, I believe that we can promote a direction for future work that encourages greater theoretical construction in the coming years.

\section{Are we reflecting on the terms and concepts we use?}

A component that can hinder the theoretical construction of the discipline is linked to the use of terms that are unclear and are not always defined in research. According to McClatchey (2005), ethnobotanical studies have used a set of imprecise terms that are very general and lead to confusion among peers. In this case, I think it is necessary to reflect more and more on the terms we use, their precision (MClatchey 2005), as well as the important concepts used in ethnobiology. For example, the study by Reyes-García et al. (2007) has highlighted the need for conceptual standardization in ethnobotanical studies 
that investigate inter-individual variations in local knowledge.

To illustrate an interesting case, Albuquerque and Hurrell (2010) point out that different terms with the prefix "ethno" have been proposed, although without following a reflection on the differences and limits between these different terms. In addition, the authors also indicate that the term ethnobotany has been used with different meanings throughout the studies, suggesting that researchers have performed little theoretical and epistemological reflection in the field (Albuquerque and Hurrell 2010). For example, ethnobotany can be thought as the "science of the other", the knowledge belonging to the studied human groups. In this case, I think that ethnobotany would be the knowledge of one or more cultures on plants and the researcher's objective would involve registering and organizing that knowledge. On the other hand, ethnobotany can be interpreted as the knowledge developed by scientists who seek to study people's relationships with plants in different cultures (Albuquerque and Hurrell 2010). Thus, the researcher would collect data on human knowledge and behavior in relation to plants, analyzing this data from a scientific view (to answer questions, test hypotheses, following the scientific method) that does not belong to the studied group. Confusions about the meaning of the term ethnobotany can occur in several descriptive studies that use expressions such as ethnobotanical knowledge of a community $X$. Considering the frequency of using these expressions without clarifying their meaning, a young researcher in the field, for example, can use these expressions without reflecting on its epistemological consequences. The confused use of these terms can lead to young researchers in the area confusing the object of research with science, as pointed out by Albuquerque (2013).
In addition to the confusion of terms among researchers in our field, when observing the interdisciplinary nature of ethnobiology, the dialogue with different disciplines poses the challenge of reflecting on the concepts that we import from other sciences. For example, more and more ethnobiological studies are using the idea of resilience based on the dialogue with ecological scenarios to investigate the dynamics of systems based on the knowledge and practices of human groups involving biota (Ladio and Lozada 2008; Reyes-García et al. 2014; Díaz-Reviriego et al. 2016; Torres-Avilez et al. 2019). However, Ferreira Júnior et al. (2015) pointed three different interpretations on resilience present in ethnobiological studies. These were: (1) structuralist interpretation, based only on the number of resources known and used by a group to infer about the system's resilience; (2) functionalist interpretation, which takes into account the functions exercised by the resources in the system; (3) processual interpretation, focusing not only on the functions but also on the processes that shape the systems, as important for assessing resilience. These different interpretations show that we need to assess how we are importing concepts from other areas, in addition to suggesting that we should always make it clear which interpretation is used in our works, to avoid misinterpretations in future works that use the same scenario.

Still according to Albuquerque and Hurrell (2010), when considering the different interpretations of terms between the studies, it would be interesting to promote an integration among researchers to reflect on the different uses of the terms and how it affects the advancement of knowledge in ethnobotany. This raises an interesting point that I make in this manuscript. Even if we have different visions and approaches within 
ethnobiology, which in fact is necessary for the construction of any scientific discipline, it would be ideal to propose integrations in research programs aimed at research questions and common objectives. Considering the different perspectives for ethnobotanical studies, these common research questions would be tackled in different ways so that we have a complete picture of the complexity involving interactions between people and biota. Thus, the different perspectives would complement each other to meet common sets of questions and objectives.

\section{The methodological debate can not be misaligned of their theoretical contributions}

In addition to the confusion between the object of study and ethnobiology as a science, there also appears to be another confusion between science and the methodological approach employed. Recently, in Brazil, Ming and Hidalgo (2020) showed an interview by the authors with the recently deceased Dr. Javier Caballero, who clearly defends that, in addition to the debate on qualitative and quantitative methods, it is necessary to reflect on the question of research first to define the best methodological approach to follow. This refers to a recent history in ethnobiology, with the emergence of "quantitative ethnobotany", which has appeared in several publications since the 1990s. Quantitative ethnobotany has emerged as a response to criticisms related to low scientific quality in ethnobotanical studies (see Phillips and Gentry 1993a,b). However, subsequent publications began to focus more on quantitative indices than on building research questions relevant to advancing scientific knowledge.
The study by Ramos et al. (2012) observed that most of the ethnobotanical works that cited the studies by Phillips and Gentry (1993b) and Bennett and Prance (2000), which are among the most cited articles in the area and relevant from the theoretical point of view, did not consider the theoretical contributions or methodological aspects of these studies. Besides that, the authors observed the presence of more citations related to methodological than theoretical contributions, which may be associated with the idea that a good scientific work must involve quantification (not necessarily a theoretical contribution) (see Ramos et al. 2012). In this sense, when considering the increase in the number of studies that use quantitative and statistical methods without necessarily accompanying an advance in scientific knowledge in the area, Albuquerque (2013) indicates that researchers have confused the (quantitative) method as a synonym for good science.

Confusing the method with science has a negative consequence for the theoretical advance of ethnobiology, since researchers invest more in the methodological approach in their studies than in building relevant questions or testing hypotheses. In this case, Albuquerque (2009) argues that we need to abandon the discussions that only seek to assess whether qualitative or quantitative methods are better for conducting ethnobotanical investigations. It would be more interesting to organize systematic investigations that favor progress in understanding the relationships between people and plants, which employ qualitative and/or quantitative methods (Albuquerque 2009). This does not mean that reflecting on methodological approaches is not important, but that they are focused on how much each approach can help us answer relevant questions. The simple debate between a 
qualitative-quantitative approach without a theoretical reflection (questions and hypotheses) has not led to an advance in the knowledge of a science as important as ethnobiology to meet increasingly complex contemporary challenges linked to peopleenvironment relations.

\section{Are we proposing common research agendas in ethnobiology?}

According to McClatchey (2006), the low quality of published ethnobotanical studies may be associated with unequal access to quality articles and texts on research methods among researchers from different countries. However, this reality has been modified in the last 10 years, with greater access to articles available on the internet, the presence of Open Access journals specialized in the field of ethnobiology (for example, Journal of Ethnobiology and Ethnomedicine, Ethnobotany Research and Applications, Ethnobiology and Conservation and Ethnobiology Letters), and with the production of new books that highlight research methods in ethnobiology and ethnoecology (see Albuquerque et al. 2014; 2019b). Particularly in the last 10 years, the problem of low quality of studies can no longer be justified by the lack of access to quality materials (see Albuquerque 2013). We are certainly dealing with a more complex problem. In addition to the points discussed in the previous topics (confusion between the object of study and the method with science), I believe that we still need to move forward in a joint effort to build common research agendas.

A set of publications in ethnobiology has placed the need for agendas to direct ethnobiological studies. For example, Albuquerque (2013) points out the need to build global research strategies and to create common research agendas that can guide the conduct of new research. These agendas may involve regional investigations with standardized methods that allow the use of data collected in different areas to answer questions at a global level (Albuquerque 2013). For example, the recent macroethnobiological approach may favor the realization of ethnobiological studies aimed at answering questions on larger spatial scales (Albuquerque and Medeiros 2012; Gutiérrez-Santillán et al. 2019), allowing a targeting of research agendas. In this case, it is important in the macroethnobiological approach to employ systematic reviews and meta-analysis, which require local studies in different regions to collect data in a standardized way to allow comparisons (Albuquerque and Medeiros 2012; Gutiérrez-Santillán et al. 2019).

In the last 10 years, researchers have presented a set of theoretical, methodological and practical questions that can direct investigations in ethnobotany (Albuquerque et al. 2019c) and in ethnopharmacology (Reyes-García 2010), contributing to the construction of common agendas. In addition, several studies have produced theoretical scenarios and hypotheses that can help to build research agendas aimed at testing their predictions in different environments (see, for example, Johns 1990; Phillips and Gentry 1993a,b; Albuquerque and Ferreira Júnior 2017; Albuquerque et al. 2019a). Gaoue et al. (2017) synthesized the theoretical advances of ethnobiology, highlighting a set of hypotheses developed, and some of them tested, over time. Finally, the work of Ludwig and El-Hani (2020) presents perspectives for new paths for theoretical reflections and practical actions related to ethnobiology.

With this diversity of scenarios and hypotheses present in ethnobiology, it would 
be advisable for any researcher in the field to access research questions, theoretical scenarios and hypotheses already developed before starting any new study. This is important both to test hypotheses that have not yet been investigated in different environments and to develop new hypotheses based on theoretical scenarios constructed in ethnobiology or in other disciplines it dialogues with.

The exercise of building common research agendas will be important to bring answers to increasingly complex socialecological challenges on the planet. The recent case involving the COVID-19 pandemic illustrates how much ethnobiological studies in the future must modify their research strategies (from a theoretical and practical point of view) to consider the complexity involving the relationships between people and the environment. For example, Volpato et al. (2020) points out that the current pandemic imposes on ethnobiological studies a direction of questions based on scenarios from different disciplines that consider processes that occur in multiple temporal and spatial scales. In this case, human cognitive biases can influence people from different regions not to notice and not to prepare for certain environmental threats (as in the case of the current pandemic of COVID-19), particularly when they are caused by factors (such as human actions directed at environment) that require time for its consequences to be noticed (see Gonçalves-Souza et al. 2020). All of these are relevant issues for future ethnobiological studies, so that it can meet current challenges associated with problems of a social-ecological nature.

\section{FINAL CONSIDERATIONS}

For Ethnobiology to experience a significant theoretical advance in the coming decades, I believe that it is relevant to think about the above points and clearly accept the complexity of ethnobiology as scientific knowledge. We can no longer confuse the object of study and the method with the science. Maintaining these misinterpretations can even delay the construction of research agendas for the future.

\section{ACKNOWLEDGEMENTS}

The author acknowledges Dr. Ulysses Paulino Albuquerque for the important considerations in the first version of this manuscript.

\section{CONFLICTS OF INTEREST}

The author has no conflicts of interest to declare.

\section{REFERENCES}

Albuquerque UP (2009) Quantitative
ethnobotany or quantification in
ethnobotany? Ethnobotany Research \&
Applications $7: 1-3$.

Albuquerque UP (2013) How to improve the quality of scientific publications in ethnobiology. Ethnobiology and Conservation 2:4.

Albuquerque UP, Ferreira Júnior WS (2017) What do we study in evolutionary ethnobiology? Defining the theoretical basis for a research program. Evolutionary Biology $44: 206-215$

Albuquerque UP, Hanazaki N (2009) Five problems in current ethnobotanical research and some suggestions for strengthening them. Human Ecology 37:653-661. 
Albuquerque UP, Hurrell JA (2010) Ethnobotany: one concept and many interpretations. In: Albuquerque UP, Hanazaki N (eds) Recent developments and case studies in ethnobotany. SBEE, NUPEEA, Recife, pp. 8799.

Albuquerque UP, Medeiros PM (2012) Systematic reviews and meta-analysis applied to ethnobiological research. Ethnobiology and Conservation 1:6.

Albuquerque UP, Cunha LVFC, Lucena RFP, Alves RRN (2014) Methods and techniques in ethnobiology and ethnoecology. Springer, New York.

Albuquerque UP, Medeiros PM, Ferreira Júnior WS, Silva TC, Silva RRV, Gonçalves-Souza T (2019a) Social-Ecological Theory of Maximization: basic concepts and two initial models. Biological Theory 14:73-85.

Albuquerque UP, Lucena RFP, Cunha LVFC, Alves RRN (2019b) Methods and techniques in ethnobiology and ethnoecology. 2 ed. Springer, New York.

Albuquerque UP, Nascimento ALB, Soldati GT, Feitosa IS, Campos JLA, Hurrell JA, Hanazaki N, Medeiros PM, Silva RRV, Ludwinsky RH, Ferreira Júnior WS, Reyes-García V (2019c) Ten important questions/issues for ethnobotanical research. Acta Botanica Brasilica 33:376-385.

Bennett BC, Prance GT (2000) Introduced plants in the indigenous pharmacopoeia of northern South America. Economic Botany 54:90-102.

Díaz-Reviriego I, Fernández-Llamazares A, Salpeteur M, Howard PL, Reyes-García V (2016) Gendered medicinal plant knowledge contributions to adaptive capacity and health sovereignty in Amazonia. Ambio 45:S263S275.

Ferreira Júnior WS, Nascimento ALB, Ramos MA, Medeiros PM, Soldati GT, Santoro FR, Reyes-García V, Albuquerque UP (2015) Resilience and adaptation in socialecological systems. In: Albuquerque UP, Medeiros PM, Casas A (eds) Evolutionary Ethnobiology. Springer, New York, pp. 105-119.

Gaoue OG, Coe MA, Bond M, Hart G, Seyler BC, McMillen H (2017) Theories and major hypotheses in ethnobotany. Economic Botany 71:269-287.
Gonçalves-Souza, T, Diniz-Filho JAF, Albuquerque UP (2020) Why scientific information does not necessarily impact the decisions by human society. Ethnobiology and Conservation 9:11.

Gutiérrez-Santillán TV, Valenzuela-Galván D, Albuquerque UP, Reyes-Zepeda F, ArellanoMéndez LU, Mora-Olivo A, Vázquez L (2019) The spatiotemporal scale of ethnobiology: a conceptual contribution in the application of meta-analysis and the development of the macro-ethnobiological approach. In: Albuquerque UP, Lucena RFP, Cunha LVFC, Alves RRN (eds) Methods and techniques in ethnobiology and ethnoecology. Springer, New York, pp 127-147.

Johns T (1990) With bitter herbs they shall eat it: chemical ecology and the origins of human diet and medicine. University of Arizona Press, Tucson.

Ladio AH, Lozada M (2008) Medicinal plant knowledge in rural communities of NorthWestern Patagonia, Argentina. A resilient practice beyond acculturation. In: Albuquerque UP, Ramos MA (eds) Current topics in ethnobotany. Research Signpost, India, pp 3953.

Ludwig D, El-Hani CN (2020) Philisophy of ethnobiology: understanding knowledge integration and its limitations. Journal of Ethnobiology 40:3-20.

McClatchey WC (2005) Exorcizing misleading terms from ethnobotany. Ethnobotany Research \& Applications 3:1-4.

McClatchey W (2006) Improving the quality of international ethnobotany research and publications. Ethnobotany Research \& Applications 4:1-9.

Ming LC, Hidalgo AF (2020) Métodos quantitativos não são a salvação de toda a lavoura etnobotânica: o que diz Javier Caballero. Ethnoscientia 5.

Phillips O, Gentry AH (1993a) The useful plants of Tambopata, Peru: II. Additional hypothesis testing in quantitative ethnobotany. Economic Botany 47:33-43.

Phillips O, Gentry AH (1993b) The useful plants of Tambopata, Peru: I. Statistical hypotheses tests with a new quantitative technique. Economic Botany 47:15-32. 
Ramos MA, Melo JG, Albuquerque UP (2012) Citation behavior in popular scientific papers: what is behind obscure citations? The case of ethnobotany. Scientometrics 92:711-719.

Reyes-García V, Martí N, McDade T, Tanner S, Vadez V (2007) Concepts and methods in studies measuring individual ethnonobtanical knowledge. Journal of Ethnobiology 27:182-203.

Reyes-García V (2010) The relevance of traditional knowledge systems for ethnopharmacological research: theoretical and methodological contributions. Journal of Ethnobiology and Ethnomedicine 6:32.

Reyes-García V, Aceituno-Mata L, Calvet-Mir L, Garnatje T, Gómez-Baggethun E, Lastra JJ, Ontillera $R$, Parada $M$, Rigat $M$, Vallès $J$, Vila $S$, Pardo-de-Santayana M (2014) Resilience of traditional knowledge systems: The case of agricultural knowledge in home gardens of the Iberian Peninsula. Global Environmental Change 24:223-231.

Reyes-García V, Balbo AL, Gómez-Baggethun E, Gueze M, Mesoudi A, Richerson PJ, RubioCampillo X, Ruiz-Mallén I, Shennan S (2016) Multilevel processes and cultural adaptation: examples from past and present small-scale societies. Ecology and Society 21:2.
Sõukand R, Stryamets N, Fontefrancesco MF, Pieroni A (2020) The importance of tolerating interstices: Babushka markets in Ukraine and Eastern Europe and their role in maintaining local food knowledge and diversity. Heliyon 6:e03222.

Torres-Avilez W, Nascimento ALB, Santoro FR, Medeiros PM, Albuquerque UP (2019) Gender and its role in the resilience of local medical systems of the Fulni-ô people in NE Brazil: Effects on structure and functionality. Evidence-Based Complementary and Alternative Medicine 2019:8313790.

Volpato G, Fontefrancesco MF, Gruppuso P, Zocchi DM, Pieroni A (2020) Baby pangolins on my plate: possible lessons to learn from the COVID-19 pandemic. Journal of Ethnobiology and Ethnomedicine 16:19.
Received: 19 May 2020

Accepted: 20 May 2020

Published: 22 May 2020 